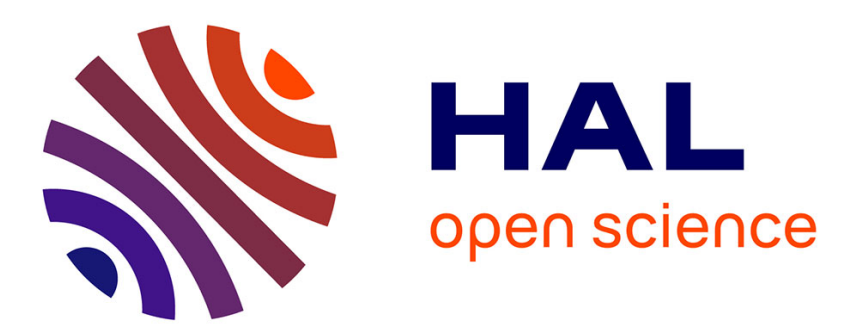

\title{
Electrochemically Modulated Liquid-Liquid Extraction for Sample Enrichment
}

\author{
Maizatul Najwa Jajuli, M. Hazwan Hussin, Bahruddin Saad, Afidah Abdul
} Rahim, Marc Hébrant, Grégoire Herzog

\section{- To cite this version:}

Maizatul Najwa Jajuli, M. Hazwan Hussin, Bahruddin Saad, Afidah Abdul Rahim, Marc Hébrant, et al.. Electrochemically Modulated Liquid-Liquid Extraction for Sample Enrichment. Analytical Chemistry, 2019, 91 (11), pp.7466-7473. 10.1021/acs.analchem.9b01674 . hal-021774662

\section{HAL Id: hal-02177462 \\ https://hal.univ-lorraine.fr/hal-02177462}

Submitted on 9 Jul 2019

HAL is a multi-disciplinary open access archive for the deposit and dissemination of scientific research documents, whether they are published or not. The documents may come from teaching and research institutions in France or abroad, or from public or private research centers.
L'archive ouverte pluridisciplinaire HAL, est destinée au dépôt et à la diffusion de documents scientifiques de niveau recherche, publiés ou non, émanant des établissements d'enseignement et de recherche français ou étrangers, des laboratoires publics ou privés. 


\title{
Electrochemically modulated liquid-liquid extraction for sample enrichment
}

\author{
Maizatul Najwa Jajuli, ${ }^{1,2}$ M. Hazwan Hussinn ${ }^{2}$, Bahruddin Saad, ${ }^{2,3}$ Afidah Abdul \\ Rahim, ${ }^{2}$ Marc Hébrant, ${ }^{1}$ Grégoire Herzog ${ }^{1 *}$
}

${ }^{1}$ Laboratoire de Chimie Physique et Microbiologie pour les Matériaux et l'Environnement (LCPME), UMR 7564, CNRS - Université de Lorraine, 405 rue de Vandoeuvre, Villers-lès-Nancy, F-54600, France.

${ }^{2}$ Analytical Chemistry Section - School of Chemical Sciences - Universiti Sains Malaysia - 11800 Penang - Malaysia

${ }^{3}$ Fundamental and Applied Sciences Department - Universiti Teknologi Petronas - 32610 Seri Iskandar, Perak -Malaysia

This document is a postprint. Final version has been published in Analytical Chemistry, 2019, 91, 7466-7473 (http://dx.doi.org/10.1021/acs.analchem.9b01674).

* Corresponding author: gregoire.herzog@univ-lorraine.fr;

\begin{abstract}
A new sample preparation method is proposed for the extraction of pharmaceutical compounds (Metformin, Phenyl biguanide, and Phenformin) of varied hydrophilicity, dissolved in an aqueous sample. When in contact with an organic phase, an interfacial potential is imposed by the presence of an ion, tetramethylammonium $\left(\mathrm{TMA}^{+}\right)$, common to each phase. The interfacial potential difference drives the transfer of ionic analytes across the interface and allows to reach up to nearly $100 \%$ extraction efficiency and a 60-fold enrichment factor in optimised extraction conditions as it is determined by HPLC analysis.
\end{abstract}




\section{Introduction}

Sample preparation is an important step of analytical procedures as it allows (i) the transfer of target analytes from a matrix incompatible with an analytical technique to a better suited one; and / or (ii) the preconcentration of analytes to work within the operating concentration range of the selected analytical technique; and / or (iii) the removal of interfering molecules and particles. Aqueous samples can be prepared for chromatographic analysis by liquid-liquid extraction. In such cases, target analytes are extracted by partition between two immiscible phases (generally an aqueous sample and an organic acceptor phase). Such an approach is most suitable for hydrophobic analytes as they will transfer easily to the organic phase unlike hydrophilic ones that will remain in the aqueous sample. In the case of hydrophilic and ionic analytes, the extraction efficiency can be improved through: (i) pH change to make the analytes more soluble in the organic phase; or (ii) the dissolution of additives in the aqueous to form ion pairs and facilitate the phase transfer. Another approach consists of using an electric field as a driving force for the transfer of ionized analytes from the aqueous to the organic phase. ${ }^{1-3}$ Three-phase systems have been developed with two aqueous phases are separated by a thin organic phase (c.a. $100 \mu \mathrm{m}$ or thinner) supported by a membrane. ${ }^{4-6}$ An electric field of typically several tens of $\mathrm{V}$ is applied between the electrodes in each aqueous phase to force the transfer of drugs and peptides $^{4}$ through the supported lipids membrane. More recently, microfluidic devices were designed to allow on-chip electro-membrane extraction in order to reduce sample volumes and improve extraction yield..$^{7-12} \mathrm{~A}$ simpler approach used three phases where the acceptor aqueous phase was a drop hanging from a conductive tip in an organic phase in contact with the aqueous sample. After application of the electric field, the contents of the acceptor aqueous drop was analysed by nanoelectrospray ionisation - direct infusion - mass spectrometry. ${ }^{13}$ This method relies on relatively high voltage (between 10 and $300 \mathrm{~V}$ ), which may cause a hazard to the operators. ${ }^{14}$

Electrochemistry at the interface between two immiscible electrolyte solutions (ITIES) allows ion transfer at lower applied potentials (generally in the $\pm 1 \mathrm{~V}$ range). The ITIES is polarised by the application of a potential difference across the interface with a potentiostat. Variation of the interfacial potential difference modulates the ion partition on either side of the interface and this phenomenon has been harnessed to the investigation of redox catalysis ${ }^{15}$ or sensing ${ }^{16}$ among other applications. Experimental set-up based on electrochemistry at ITIES were used for the extraction of ions. ${ }^{17-19}$ In these studies, the application of an interfacial potential between an aqueous solution containing the ions of interest flowing over a static hydrophobic phase, has caused the extraction of ions. However, there are two main issues for sample preparation applications. First, electrochemistry at the ITIES is a process that is limited by the diffusion of species. As a consequence, the low surface area-to-volume ratio of the electrochemical cells used limited the extraction efficiency to $10 \%$, which is not acceptable 
for sample preparation applications. ${ }^{17-19}$ Mass transport can be improved by the design of hydrodynamic liquid-liquid cells, ${ }^{20-23}$ for which limiting currents were achieved in agreement with Levich equation. ${ }^{24}$ The second limitation is the organic phase in which target ions are extracted to. Some organic solvents are not suitable for chromatography analysis, and thus dealing with aqueous samples is generally preferred. As for electro-membrane extraction, supported liquid membranes were also used with two polarised water-oil interfaces ${ }^{25-29}$ and hence allowed the injection of an aqueous acceptor solution for the chromatographic analysis. A complex rotor was designed to improve efficiently the mass transport but this would be impractical for routine sample preparation prior to chromatographic analysis.

We propose here to combine the droplet liquid-liquid extraction with the chemical polarisation of the interface between two immiscible solutions to prepare samples before chromatographic analysis. The interfacial potential was controlled through the dissolution of a common ion in each phase, without the use of electrodes and of a potentiostat, according to the method described in the literature. ${ }^{30,31}$ This distribution of the common ion $i$, with a formal transfer potential $\Delta_{o}^{w} \phi_{i}^{0 \prime}$, in either phases imposes the interfacial potential, $\Delta_{o}^{w} \phi$, according to the Nernst-like equation:

$$
\Delta_{o}^{w} \phi=\Delta_{o}^{w} \phi_{i}^{0^{\prime}}+\frac{R T}{z F} \ln \frac{C_{i}^{o}}{C_{i}^{w}}
$$

We investigated here the extraction of three biguanide cations: metformin (1,1-dimethylbiguanide), phenformin (Phenylethylbiguanide) and phenylbiguanide, whose transfer across the ITIES has already been reported. ${ }^{32}$ Molecules of the biguanide family have been used in the treatment of type 2 diabetes since the $1950 \mathrm{~s}^{33}$ Although the medication of phenformin has been discontinued since the 1970s, metformin is nowadays one of the most prescribed antidiabetic medication. The choice of these three drugs offers a span of hydrophilicity with $\log P$ (octanol-water partition coefficient) values ranging from -1.82 (metformin) to 0.41 (phenformin). These drugs can also be found under the dicationic, cationic and neutral forms. Metformin is a highly polar molecule with a great solubility in water and poor solubility in lipids making it difficult to extract from an aqueous matrix. ${ }^{34}$ Solid phase extraction is a one of the preferred methods of sample preparation for chromatographic analysis and has been used for the extraction of metformin. ${ }^{35-37}$ Due to the hydrophilic nature of metformin, extraction efficiencies for metformin range from $16 \%$ to $105 \%$ depending on the nature of the sample and the concentrations. Sample preparation based on liquid-liquid microextraction was developed based on the formation of an ion pair between biguanides (metformin and buformin) and di-(2ethylhexyl)phosphoric acid, which favours a more efficient liquid-liquid extraction with $94-108 \%$ recoveries. ${ }^{38}$ Metformin, buformin and phenformin preconcentration was also achieved with a saltingout assisted liquid-liquid extraction with similar success. ${ }^{39}$ 
We studied here a novel approach for liquid-liquid extraction for the sample preparation of aqueous samples containing cationic analytes. This instrument-free method is based on ion transfer modulated by the application of an interfacial potential controlled by the distribution of a common ion between the two phases.

\section{Experimental section}

\section{Reagents}

Lithium chloride (97\%), metformin hydrochloride (97\%), phenyl biguanide hydrochloride (98\%), phenformin hydrochloride (97\%), tetraethylammonium chloride $\left(\mathrm{TEA}^{+}, 99 \%\right)$, sodium phosphate monobasic monohydrate (98\%), and triethylamine (99.5\%), bis(triphenylphosphoranylidene) ammonium chloride $\left(\mathrm{BTPPA}^{+} \mathrm{Cl}^{-}, 97 \%\right)$ and potassium tetrakis(4-chlorophenylborate) ( $\mathrm{K}^{+} \mathrm{TPBCl}$, 98\%) were purchased from Sigma Aldrich. Tetramethylammonium chloride $\left(\mathrm{TMA}^{+}, 99 \%\right)$ was purchased from Fluka BioChemika. Sodium hydroxide (97\%), ortho-phosphoric acid (85\%), both from BDH Prolabo and hydrochloric acid (Merck, 37\%) were used to adjust pH. All aqueous solutions were prepared in ultrapure water (18.2 M $\Omega \mathrm{cm}$, Elga Water). HPLC-grade acetonitrile and 1, 2-dichloroethane (DCE) were purchased from Sigma Aldrich. $\mathrm{BTPPA}^{+} \mathrm{TPBCl}^{-}$and $\mathrm{TMA}^{+} \mathrm{TPBCl}^{-}$were prepared by metathesis and dissolved in DCE according to the published procedure. ${ }^{40}$

\section{Control of the interfacial potential difference $\left(\Delta_{o}^{w} \phi\right)$}

The potential difference between the two immiscible electrolyte solutions was controlled by either the help of a potentiostat or by distribution of a common ion between the two phases. For cyclic voltammetry experiments, a custom-made borosilicate glass cell was used $\left(A_{\text {interface }}=1.10 \mathrm{~cm}^{2}\right)$ to host the biphasic system (Figure SI1). The interfacial potential difference was measured with one reference electrode in each phase and the current variation linked to charge transfer across the liquid-liquid interface were recorded thanks to one Pt mesh electrode in each phase, acting as counter-electrodes.

The formal transfer potential of $\mathrm{TEA}^{+}, \Delta_{o}^{w} \phi_{T E A^{+}}^{0^{\prime}}=0.049 \mathrm{~V}^{41}$ was used to calibrate the potential window. TEA ${ }^{+}$was added to the aqueous phase of the electrochemical cell at the end of a series of experiments for potential calibration purposes.

To extract targeted drugs, the potential difference across the interface was applied by controlling the distribution of a common ion. $\mathrm{TMA}^{+} \mathrm{Cl}^{-}$and $\mathrm{TMA}^{+} \mathrm{TPBCl}^{-}$salts were dissolved in the aqueous and the organic phase respectively to control the interfacial potential difference, according to Nernst-like equation (Eq. 2). 


$$
\Delta_{o}^{w} \phi=\Delta_{o}^{w} \phi_{T M A^{+}}^{0^{\prime}}+\frac{R T}{z F} \ln \frac{\left[T M A^{+}\right]_{o}}{\left[T M A^{+}\right]_{w}}
$$

where $\Delta_{O}^{w} \phi_{T M A^{+}}^{0 \prime}$ is the formal transfer potential of TMA ${ }^{+}$between aqueous and DCE $(+0.160 \mathrm{~V}),{ }^{42}$ and $\left[\mathrm{TMA}^{+}\right]_{\mathrm{o}}$ and $\left[\mathrm{TMA}^{+}\right]_{\mathrm{w}}$ are the $\mathrm{TMA}^{+}$concentrations in the organic and in the water phases. In our experiments, the concentrations varied between $1<\left[\mathrm{TMA}^{+}\right]_{\mathrm{o}}<10 \mathrm{mM}$ and $0.0001<\left[\mathrm{TMA}^{+}\right]_{\mathrm{w}}<50 \mathrm{mM}$, resulting in potential applied ranging from $0.141<\Delta_{o}^{w} \phi<0.414 \mathrm{~V}$. All potentials are given with respect to the Galvani potential scale.

\section{Preconcentration procedure}

The preconcentration procedure developed here is a two-step protocol, which consisted of (i) the extraction of the drug from an aqueous sample $\left(V_{a q}=6 \mathrm{~mL}\right)$ to an intermediate organic phase $\left(V_{\text {org }}=2\right.$ $\mathrm{mL})$; (ii) the back-extraction to a final aqueous phase $\left(\mathrm{V}_{\text {final }}=0.1 \mathrm{~mL}\right)$. The extraction and backextraction are controlled by the application of a chemical potential difference, $\Delta_{o}^{w} \phi$, favourable to the transfer of cations from one phase to another. The biphasic system is stirred at $600 \mathrm{rpm}$ for $900 \mathrm{~s}$ during the extraction to ensure optimal mass transport conditions and maximise ion transfer. For the back-extraction, the biphasic system is vortexed at $25 \mathrm{~Hz}$ for $90 \mathrm{~s}$ before being centrifuged for $60 \mathrm{~s}$ at $4000 \mathrm{rpm}$. The $100 \mu \mathrm{L}$ of the final aqueous phase are then collected and ready for HPLC separation. All extraction experiments are run at $\mathrm{T}=293 \mathrm{~K}$. The various conditions for the extraction and back extraction steps are listed in Table S1.

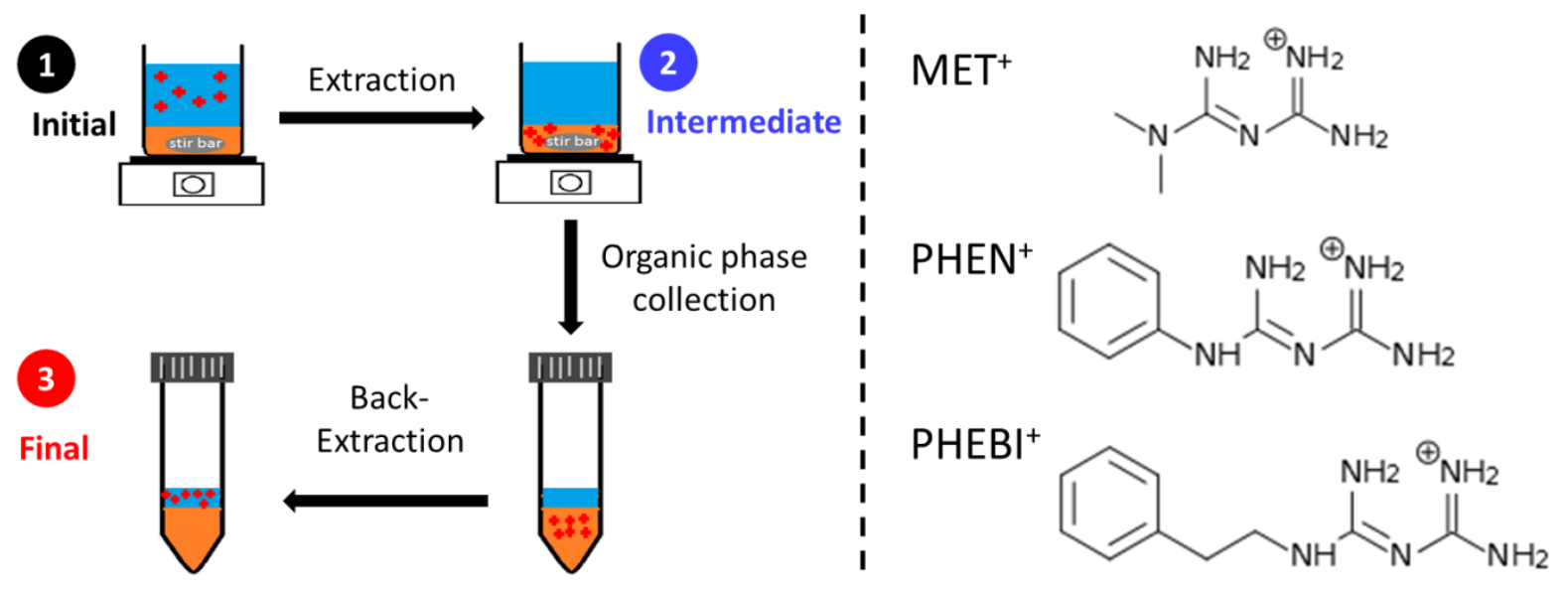

Figure 1: (Left): Experimental procedure of the electrochemically modulated liquid-liquid extraction. Target cations are extracted from the aqueous sample to organic phase before being back-extracted to a final aqueous phase. The numbers 1,2 and 3 correspond to the initial, intermediate and final stages at which the aqueous phases are analysed by HPLC. (Right): Chemical structures of the three target molecules. pKa values are given in Table SI3. 
Urine samples were spiked with 1.6 $\mathrm{MM} \mathrm{MET}^{+}, \mathrm{PHEBI}^{+}$and $\mathrm{PHEN}^{+}$and were pre-treated according to two different protocols. The first procedure consisted of diluting the urine sample with de-ionized water. The second procedure was aimed at the protein precipitation by dilution 1:3 in acetone. The samples were then vortexed for $120 \mathrm{~s}$ and centrifuged for $180 \mathrm{~s}$. The acetone was left to evaporate under a $\mathrm{N}_{2}$ stream for 30 min before being diluted 1:10 in de-ionized water. After this sample pretreatment, the following parameters were used for the extraction procedure: $\left[\mathrm{TMA}^{+}\right]_{0}=10 \mathrm{mM}$, $\left[\mathrm{TMA}^{+}\right]_{\mathrm{w}}=0.001 \mathrm{mM}, \mathrm{pH} 6, \mathrm{~V}_{\mathrm{DCE}}=2 \mathrm{~mL}, \omega=600 \mathrm{rpm}, \mathrm{t}_{\mathrm{ext}}=15 \mathrm{~min}$.

\section{HPLC parameters}

Chromatographic experiments were conducted using a Zorbax TMS (C1) $5 \mu \mathrm{m}, 80 \AA ., 4.6$ x $250 \mathrm{~mm}$ column protected by a guard column $4.6 \mathrm{~mm}$ ID x $12.5 \mathrm{~mm}$ both from Agilent. The mobile phase consisted in a $20 \mathrm{mM}$ phosphate buffer (pH 6.2): acetonitrile: triethylamine (50:50:0.2) flown at $1.3 \mathrm{~mL}$ $\min ^{-1}$ at $40^{\circ} \mathrm{C}$. It was prepared daily and degassed just before use. The device used was Shimadzu LC20. The flow rate of the mobile phase under isocratic condition. Injection volume was $20 \mu \mathrm{L}$. The detection was performed at $\lambda=230 \mathrm{~nm}$. Data was recorded using the LabSolutions software. For each sample treated by the preconcentration procedure, we injected at three stages of the procedure (Figure 1): (1) initial aqueous sample as a control experiment; (2) aqueous sample after extraction and (3) final aqueous phase. The yield of extraction, Y\%, is then determined by the following equation:

$$
\%_{\text {Extraction }}=\frac{A_{1}-A_{2}}{A_{1}} \times 100
$$

where $A_{1}$ and $A_{2}$, represent the area under the chromatographic peak at stages (1) and (2), respectively. As shown by the calibration curves for the three drugs (Figure SI2), the chromatographic peak area is proportional to the drug concentration. The second parameter calculated from the chromatography experiments is the enrichment factor, EF according to equation (4):

$$
E F=\frac{A_{3}}{A_{1}}
$$

where $A_{3}$, represent the area under the chromatographic peak at Stage 3.

The precision is expressed by relative standard deviation values. It was calculated from interday and intraday assays using nine replicates for each concentration on the same day and for six different days.

\section{Results and Discussion}

Ion transfer at the ITIES 
The transfer of the monocationic form (i.e. at $\mathrm{pH}$ 6) of metformin $\left(\mathrm{MET}^{+}\right)$, phenformin $\left(\mathrm{PHEN}^{+}\right)$and phenylbiguanide $\left(\mathrm{PHEBI}^{+}\right)$was investigated by cyclic voltammetry at the ITIES (Figure 2). For each drug, a reversible ion transfer was observed and the formal Galvani transfer potential was determined as the half-transfer potential (Table SI3). The transfer potential of the cations increased with their hydrophilic nature. Indeed, $\mathrm{MET}^{+}$, with a $\log P_{0}$ value of -1.82 (for the non-ionic form of $\mathrm{MET}^{+}$), transfers at a potential of $+0.270 \mathrm{~V}$, which is higher than the potential of $+0.186 \mathrm{~V}$ measured for $\mathrm{PHEN}^{+}\left(\log P_{0}\right.$ $=0.41)$, whereas $\mathrm{PHEBI}^{+}$has an intermediate $\left(\log P_{0}=-0.03\right)$ and formal Galvani transfer potential is + $0.256 \mathrm{~V}$. The drug transfer potential followed the same trend when the $\mathrm{pH}$ of the aqueous phase was set at $\mathrm{pH} 2$ (Figure SI3). Nevertheless, in acidic conditions, the three drugs are further protonated $(z=$ +2 ) resulting in a higher transfer potential difference. Based on those results, ionic partition diagrams $\mathrm{s}^{43,44}$ were built for each of the three targeted molecules (Figures SI4-6). Such diagrams allow the prediction of the preferred phase of these compounds depending on the Galvani potential difference applied at the liquid-liquid interface and the $\mathrm{pH}$ of the aqueous phase. If we consider a sample with a pH between 6 and 8 (corresponding the $\mathrm{pH}$ range of most real samples), the three compounds studied remain preferably in the aqueous phase at open circuit potential. For the three drugs to transfer to the organic phase, a Galvani potential difference greater than $+0.270 \mathrm{~V}$ is needed to favour their transfer to the organic phase.

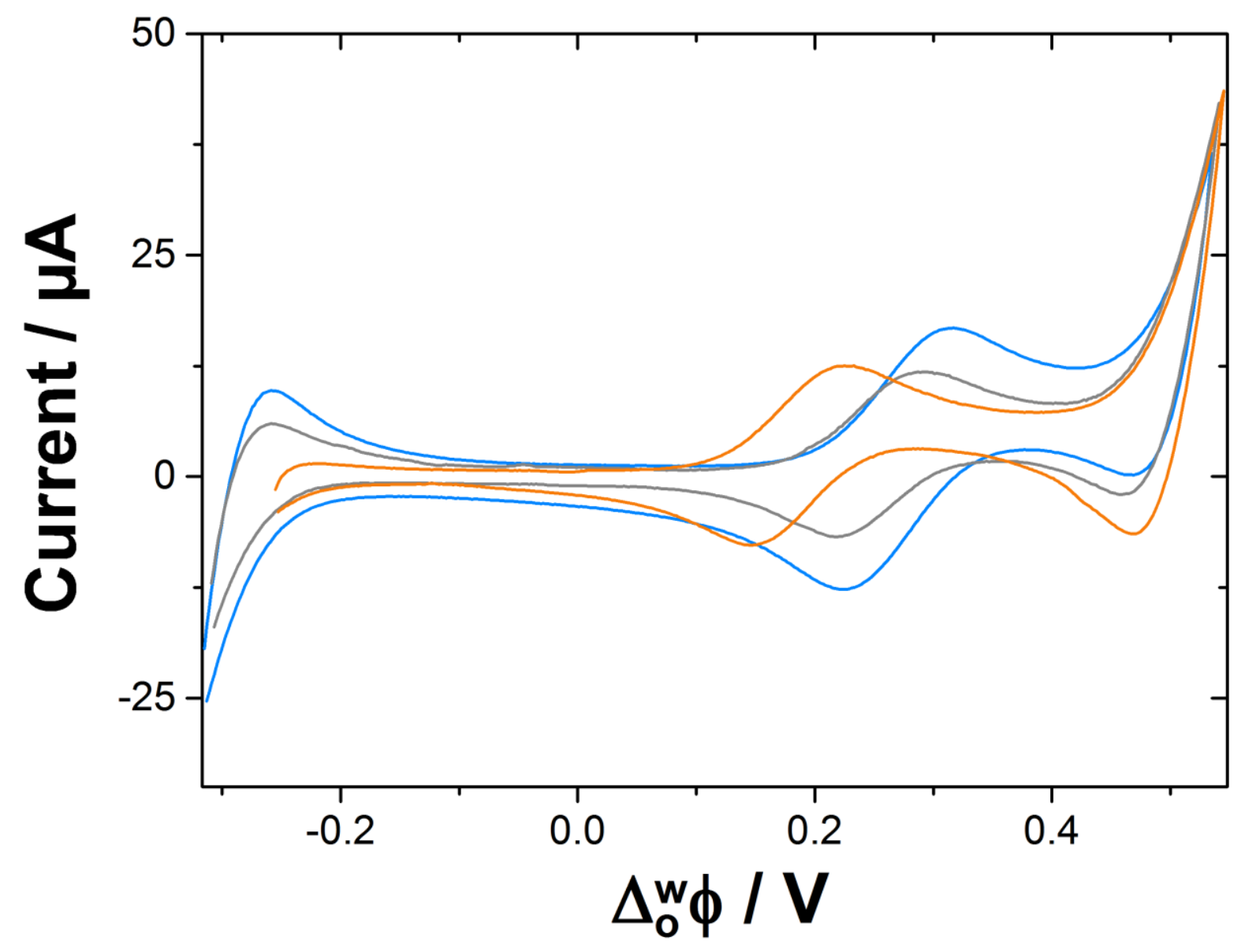


Figure 2: Cyclic voltammograms of $170 \mu \mathrm{M} \mathrm{MET}^{+}$(blue curve), $\mathrm{PHEBI}^{+}$(grey curve) and $\mathrm{PHEN}^{+}$(orange curve) transferring across the ITIES. Electrochemical cell $1, v=5 \mathrm{mV} \mathrm{s}^{-1}$.

\section{Preconcentration mechanism}

$\mathrm{TMA}^{+}$was selected as the common ion in aqueous and organic phases to establish the interfacial potential difference. The sample, containing the three targeted ions and $\mathrm{TMA}^{+}$, was placed in contact of the organic phase containing a known concentration of $\mathrm{TMA}^{+}$. The two solutions were stirred thoroughly for $900 \mathrm{~s}$ to maximise the area of contact between the two phases. The sample solution was analysed by chromatography before and after this extraction step. The organic phase was then collected and placed in contact with another aqueous solution to back-extract the three targeted ions for HPLC analysis. Chromatograms before and after extraction are shown in Figure 3 for a given set of extraction parameters. The first sample analysed contained $\mathrm{MET}^{+}, \mathrm{PHEBI}^{+}$and $\mathrm{PHEN}^{+}(164 \mu \mathrm{M}$ each) and $1 \mu \mathrm{M}$ of $\mathrm{TMA}^{+}$. The organic solution used for the extraction contained $10 \mathrm{mM}$ of $\mathrm{TMA}^{+} \mathrm{TPBCl}^{-}$. Based on these $\mathrm{TMA}^{+}$concentrations, the initial $\Delta_{o}^{w} \phi$ was $+0.392 \mathrm{~V}$, which should be sufficient to extract $100 \%$ of all three targeted ions, according to the ionic partition diagrams (Figures SI4-6). However, the extraction are much lower than expected with $27 \%$ for $\mathrm{MET}^{+}, 44 \%$ for $\mathrm{PHEBI}^{+}$and $76 \%$ for $\mathrm{PHEN}^{+}$. When the initial drug concentration is reduced down to $1.64 \mu \mathrm{M}$, extraction efficiencies increased to $84.2 \%$ for $\mathrm{MET}^{+}, 100 \%$ for $\mathrm{PHEBI}^{+}$and $100 \%$ for $\mathrm{PHEN}^{+}$although the same extraction conditions were used (Figure 3B).
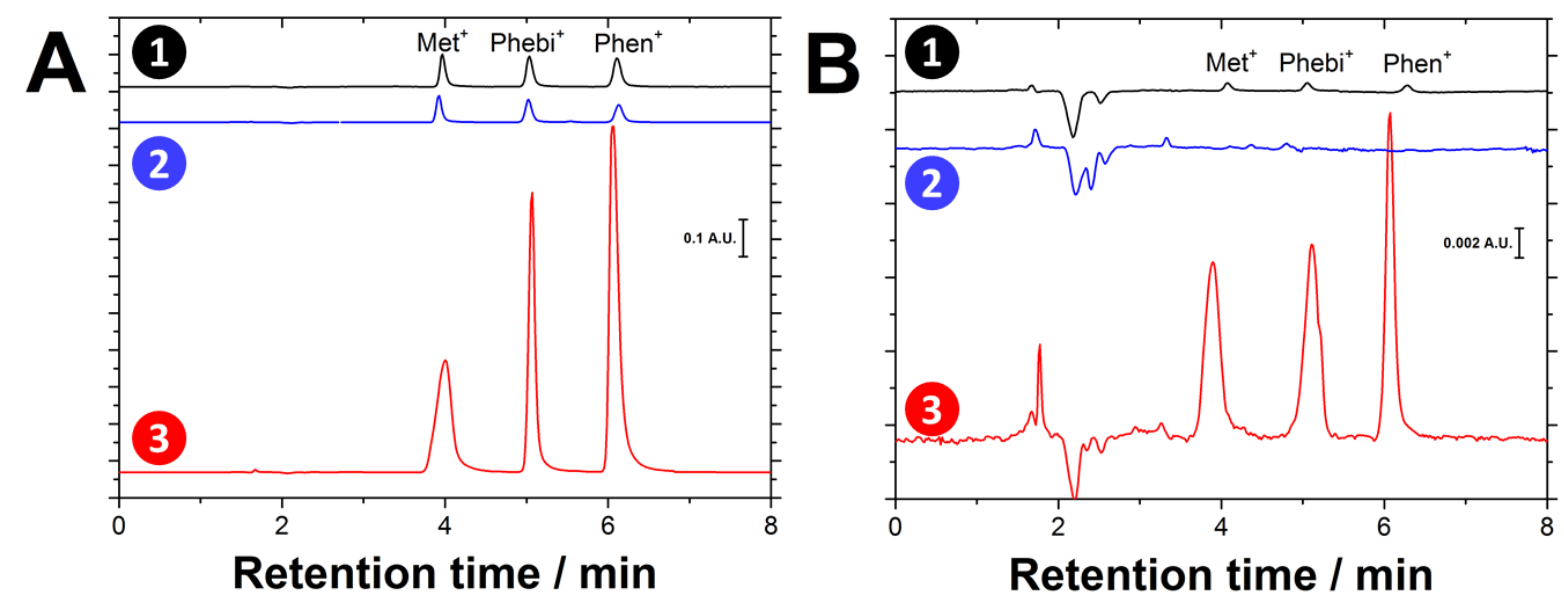

Figure 3: Chromatograms obtained for a sample containing $\mathrm{MET}^{+}, \mathrm{PHEBI}^{+}$and $\mathrm{PHEN}^{+}$at (A) $164 \mu \mathrm{M}$ each and at (B) $1.64 \mu \mathrm{M}$ each before (1) and after (2) extraction, and after back-extraction (3). Extraction conditions were $\left[\mathrm{TMA}^{+}\right]_{0}=10 \mathrm{mM},\left[\mathrm{TMA}^{+}\right]_{\mathrm{w}}=0.001 \mathrm{mM}, \mathrm{pH} 11, \mathrm{~V}_{\mathrm{DCE}}=2 \mathrm{~mL}, \omega=600 \mathrm{rpm}$, $t_{\text {ext }}=15 \mathrm{~min}$.

This variation in the extraction efficiencies achieved is linked to the ion transfer mechanism. The extraction of one mole of cation from the sample must be accompanied by the transfer of one mole of 
ion (either an anion from the sample to the organic phase or a cation from the organic phase to the sample). This co-transfer is occurring to maintain electroneutrality in both phases of the system. Due to its amphiphilic nature, $\mathrm{TMA}^{+}$is able to compensate the electric charge of both the very hydrophobic $\mathrm{TPBCl}^{-}$in the organic phase and the very hydrophilic $\mathrm{Cl}^{-}$in the aqueous phase. During the transfer of cationic drugs, the electroneutrality has to be maintained, and the lowest cost in terms of energy is by the transfer of $\mathrm{TMA}^{+}$to the organic phase to the sample. This equilibration of charge results in a variation of the interfacial potential difference, occurring as target ions are extracted. Equation (2) cannot be used here as it describes the interfacial potential difference in the presence of a single common ion. However, in the case where many ions can partition on either side of the interface, they all contribute to the interfacial potential difference. We use instead the theory that was developed in the 1980 s by Hung to calculate the Galvani potential difference at equilibrium, $\Delta_{o}^{w} \phi_{E q}^{E x t} \cdot{ }^{30,31}$ In brief, each ion is distributed between the sample and the organic phase, and for each of them we can define two functions, one for the aqueous phase, $\zeta_{i}^{w}$, and one for the organic phase, $\zeta_{i}^{o}$, (Eqs. (5) and (6)).

$$
\begin{aligned}
\zeta_{i}^{w} & =\frac{Z_{i} C_{i}^{0, w}}{1+r e^{\left[\frac{Z_{i} F}{R T}\left(\Delta_{o}^{w} \phi-\Delta_{o}^{w} \phi_{i}^{0}\right)\right]}} \\
\zeta_{i}^{o} & =\frac{r Z_{i} C_{i}^{0, o}}{1+r e^{\left[\frac{Z_{i} F}{R T}\left(\Delta_{o}^{w} \phi-\Delta_{o}^{w} \phi_{i}^{0}\right)\right]}}
\end{aligned}
$$

In these equations, $r$ is the ratio of the organic to aqueous volumes. The total sum, $\zeta_{\text {total }}$, is be calculated as follows:

$$
\zeta_{\text {total }}=\sum_{i} \zeta_{i}^{w}+\sum_{i} \zeta_{i}^{o}
$$

As equations (5) and (6) assumed equilibrium, extraction time and rotation speed were optimised (Figure SI7). Equilibrium was reached for an extraction time of $600 \mathrm{~s}$ and a rotation speed of $900 \mathrm{rpm}$. Figure 4 shows the variation of $\zeta_{\text {total }}$ as a function of the interfacial potential difference. The Galvani potential difference at equilibrium, $\Delta_{o}^{w} \phi_{E q}^{E x t}$, is reached when $\zeta_{\text {total }}=0$. The shift of $\Delta_{o}^{w} \phi_{E q}^{E x t}$ to higher values for the lower initial drug concentrations confirms the trend observed experimentally where extraction efficiencies were greater when the initial concentration decreased. A variety of parameters (analyte concentration, common ion concentration in both sample and organic phase, volume of the organic phase, $\mathrm{pH}$, rotation speed, and extraction time) were investigated to improve the extraction yield of the three drugs (Table SI1). We plotted the extraction yield for each of the three drugs studied as a function the interfacial potential difference at equilibrium, $\Delta_{o}^{w} \phi_{E q}^{E x t}$, (determined experimentally 
using the chromatograms recorded after extraction as described in SI). Experimental results were shown as data points on Figure 5 and compared to the theoretical behaviour expected from the Nernst equation. Extraction yield increased with $\Delta_{o}^{w} \phi_{E q}^{E x t}$, confirming that ion extraction can be modulated by controlling the interfacial potential.

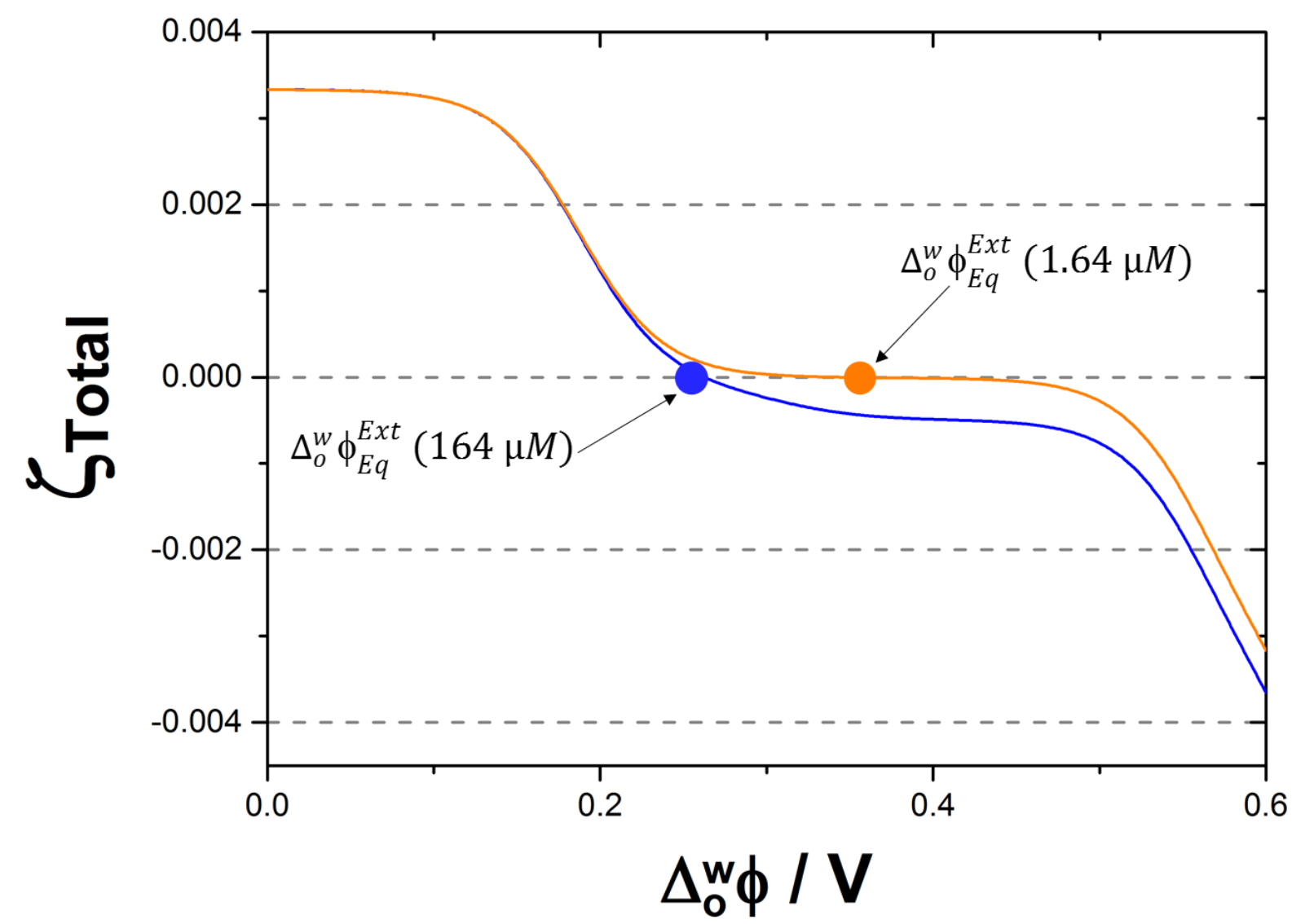

Figure 4: Dependence of $\zeta_{\text {total }}$ as a function of the interfacial potential difference, $\Delta_{o}^{w} \phi$, for extraction conditions of Figure 3. [Analyte] = $164 \mu \mathrm{M}$ for the blue curve and $1.64 \mu \mathrm{M}$ for the orange curve.

With 89 samples with 8 different parameters, a principal component analysis was run (Figure SI8). $\Delta_{o}^{w} \phi_{E q}^{E x t}(35.0 \%)$, [Analyte] (31.0\%), and [TMA $\left.{ }^{+}\right]_{o}(24.3 \%)$ contributed most to the first component (28.4\%). The principal component analysis showed that the most influential parameters for the extraction efficiency are linked to the interfacial potential difference, thus confirming the electrochemically modulated nature of the ion extraction. The second component $(19.4 \%)$ is constituted of the volume of organic phase $(44.1 \%)$, the pH (21.0\%), and the stirring (14.6\%). These parameters had a lower contribution to the extraction yield. Due to the poor solubility of the analytes 
in the organic phase, the volume of organic phase needs to sufficiently large to increase the extraction yield. By maintaining the analytes in their monocationic form (i.e. $4<\mathrm{pH}<9$, Figure SI9), the extraction potential is at the lowest value, and is hence the easiest. Based on this statistical analysis, the optimised parameters for the extraction are the following: $\left[T M A^{+}\right]_{o}=10 \mathrm{mM},\left[T M A^{+}\right]_{w}=0.001 \mathrm{mM}, V_{\text {org }}=2$ $\mathrm{mL}, \mathrm{pH}_{\text {sample }}=9$, rotation speed $=600 \mathrm{rpm}$, extraction time $=600 \mathrm{~s}$.

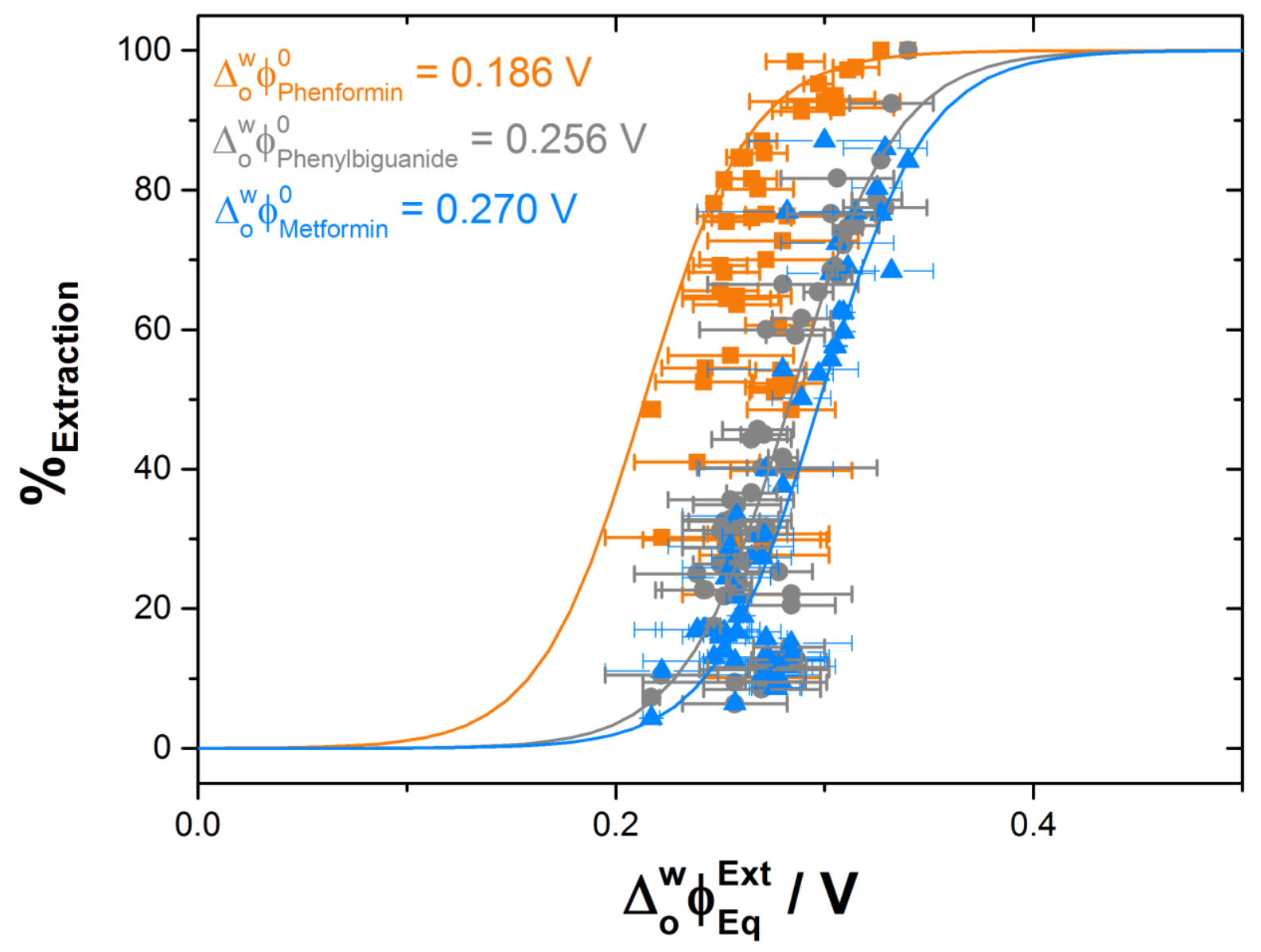

Figure 5: Extraction yield of $\mathrm{MET}^{+}$, (blue triangles) $\mathrm{PHEBI}^{+}$(grey circles) and $\mathrm{PHEN}^{+}$(orange squares) as a function of the interfacial potential difference at equilibrium $\Delta_{o}^{w} \phi_{E q}^{E x t}$. These experimental points were obtained for a variety of parameters (Table SI1). Solid lines are the expected extraction yields for each of the drugs according to Nernst equation.

The extracted drugs to the organic phase were then back-extracted to a final aqueous phase. The $\mathrm{pH}$ for the back extraction phase was set at 2 . In these acidic conditions, all three analytes were mostly dicationic and, hence, would transfer more easily to the aqueous phase. The interfacial potential was set at $+0.119 \mathrm{~V}$ with $\left[\mathrm{TMA}^{+}\right]_{\text {back }}=50 \mathrm{mM}$, which is lower than the $\Delta_{o}^{w} \phi^{1 / 2}$ of $\mathrm{MET}^{2+}, \mathrm{PHEB}^{2+}$ and $\mathrm{PHEN}^{2+}$ (Table SI3). A volume of aqueous phase for the back-extraction was selected at $0.1 \mathrm{~mL}$. Such a volume allowed to inject $20 \mu \mathrm{L}$ of solution to the HPLC. In the case of a $100 \%$ extraction yield, the expected enrichment factor is the volume ratio between the initial sample and the back extraction phase $\left(\mathrm{EF}_{\max }\right.$ 
$=60$ in our study). We plotted the \% Extraction as a function of the enrichment factor for the three analytes (Figure 6). The solid line symbolises the maximum enrichment factor expected if the back-extraction has reached $100 \%$ efficiency. Data points above the straight line indicate that the extraction was more efficient than back-extraction. As the most hydrophobic, $\mathrm{PHEN}^{+}$(orange squares) is easily extracted to the organic phase. Despite higher extraction, the enrichment factor barely reaches its expected value. On the contrary, there is a linear correlation between the \%extraction of $\mathrm{MET}^{+}$(blue triangles) and its enrichment factor (slope $=1.655, R^{2}=0.869$, for a theoretical slope of 1.667). Once MET ${ }^{+}$is extracted to the organic phase, it easily transfers back to the final aqueous phase due to its hydrophilic nature. One of the limitations of the method is the back-extraction of hydrophobic compounds, which could be improved by the use of a more hydrophobic common ion. In addition, adjusting the $\mathrm{pH}$ of the final solution to make sure that the analyte is under an ionic form would favour the back-extraction. As a control experiment, we have investigated the extraction of propranolol, a hydrophobic $\beta$-blocker, $\left(\log \mathrm{P}_{0}=3.1, \Delta_{o}^{w} \phi_{\text {Propranolol }}^{0}=0.141 \mathrm{~V}, \mathrm{pKa}=9.4\right)$. The results showed, in Figure SI10, that in the extraction conditions studied, the extraction is relatively easy with efficiencies achieved ranging from 79 to $99 \%$, depending on $\Delta_{o}^{w} \phi_{E q}^{E x t}$. However, the enrichment factor varied from 0.4 to 15.8 (while the maximum value given by the mass balance is 60 ).

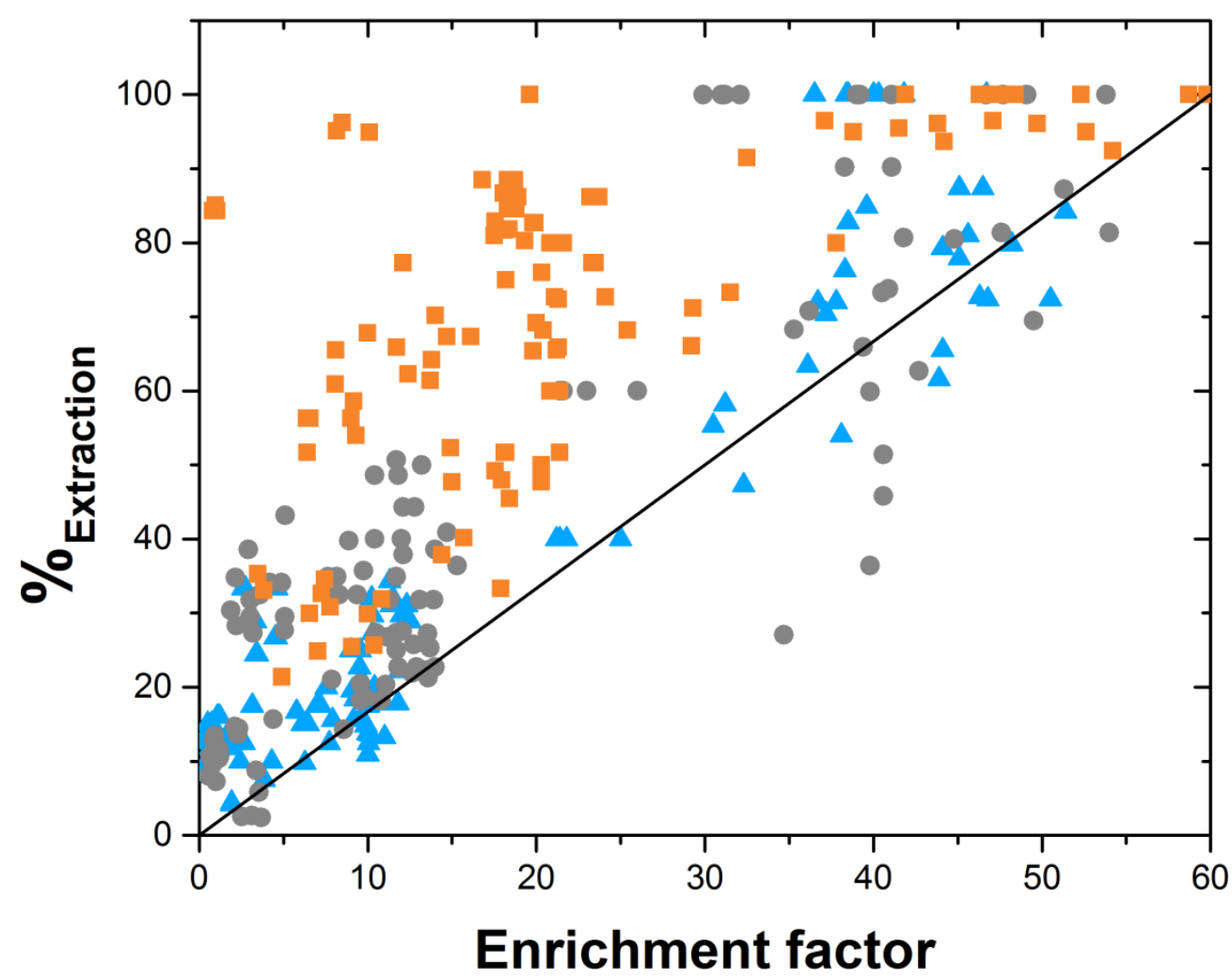


Figure 6: \%Extraction as a function of the enrichment factor for $\mathrm{MET}^{+}$, (blue triangles) $\mathrm{PHEBI}^{+}$(grey circles) and $\mathrm{PHEN}^{+}$(orange squares). The solid line represents the enrichment factor expected if backextraction efficiency is $100 \%$.

A series of three control experiments in the absence of chemical polarization were run to confirm that the ion extraction is due to the effect of the interfacial potential (Figure SI11). For the first two control experiments, the initial aqueous phase was de-ionized water with $10 \mu \mathrm{M}$ of the three drugs. For control 1, $\mathrm{pH}$ was 6.5 and for control 2, $\mathrm{pH}$ was adjusted to 11 with $\mathrm{NaOH}$ solution. For these two control experiments, the organic phase was DCE without added electrolyte. For the third control experiment, the organic phase contained $10 \mathrm{mM} \mathrm{BTTPA}{ }^{+} \mathrm{TPBCl}^{-}$, which role was to check whether ion pairing between the drugs and $\mathrm{TPBCl}^{-}$had a role in the extraction. For these three control experiments, the enrichment factor ranged between 0.02 and 1.25 (all three drugs considered). These results confirmed that chemical polarization is responsible for the drug extraction. Finally, we compared the method proposed here with other methods reported in the literature for biguanide extractions (Table SI6). The two-step extraction was achieved in 16.5 minutes, and remained faster than most existing extraction methods that often included a lengthy evaporation time. This faster analysis did not compromise the analytical performance as the LOD and LOQ achieved are in the same order of magnitude as published methods.

\section{Analytical performance}

Using optimum conditions, samples were enriched for a series of seven initial concentrations ranging from $16 \mathrm{nM}$ to $1.6 \mu \mathrm{M}$. Figure 7 showed the chromatograms of extracted analytes obtained from injection of the final aqueous phase (i.e. after sample enrichment). Method validation parameters (linearity, limit of detection (LOD), limit of quantitation (LOQ), precision) were calculated from the calibration curves established (Figure SI12) and are gathered in Table 1. Both LOD and LOQ for MET ${ }^{+}$ are improved by a factor 50 whereas the improvement is lower for $\mathrm{PHEBI}^{+}(\mathrm{a}$ factor 10$)$ and $\mathrm{PHEN}^{+}(\mathrm{a}$ factor 7), proving that the method is suitable for the sample enrichment of non-polar target analytes. The Interday and intraday assays showed an overall precision around 7 \% (Table 1). 


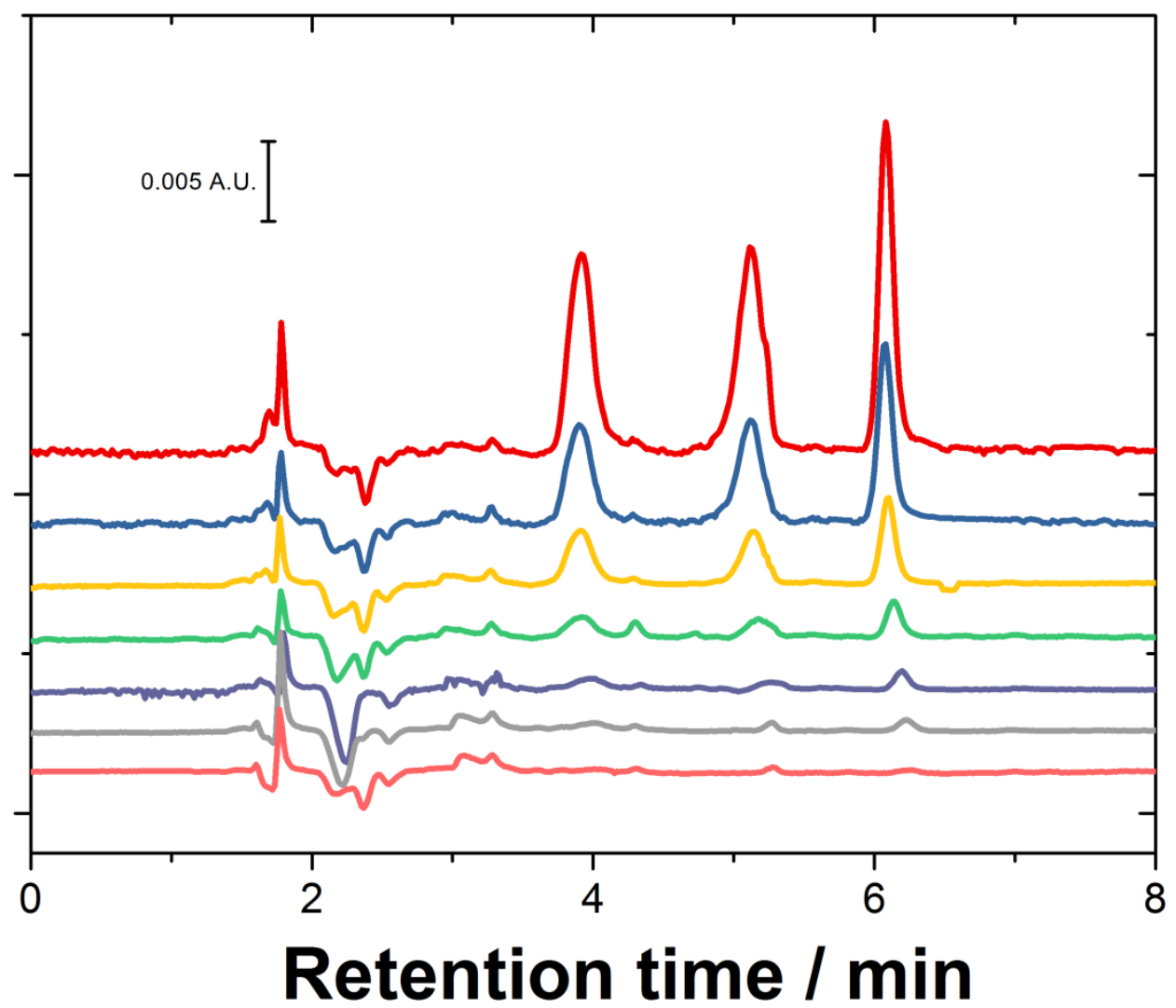

Figure 7: Chromatograms $\mathrm{MET}^{+}, \mathrm{PHEBI}^{+}$and $\mathrm{PHEN}^{+}$after sample enrichment using the optimised conditions (shown in Table SI1). Concentrations ranged from $16 \mathrm{nM}$ to $1.6 \mu \mathrm{M}$.

Urine samples from unknown donor were spiked with 1.6 $\mu \mathrm{M} \mathrm{MET}^{+}, \mathrm{PHEBI}^{+}$and $\mathrm{PHEN}^{+}$. Three urine samples were pre-treated by diluting 1:4, 1: 10 and 1:10 with deionized water to minimise matrix effects and obtain a clear interface between the two immiscible phases, according to published procedures. ${ }^{45-49} \mathrm{~A}$ fourth sample was pre-treated by protein precipitation in 1:3 acetone. The recovery test was performed using the optimized extraction parameters (Figure 8). Recoveries in the range 80 - $115 \%$ were obtained for $\mathrm{MET}^{+}$(90.2-113.7\%), $\mathrm{PHEBI}^{+}$(81.4-86.3 \%) and $\mathrm{PHEN}^{+}(82.3-86.5 \%)$ in urine pretreated by dilution. The enrichment factors were of 49.5 for $\mathrm{MET}^{+}, 59.5$ for $\mathrm{PHEBI}^{+}$and 58 for $\mathrm{PHEN}^{+}$, which are very close to the enrichment factors achieved for clean laboratory solutions. Sample pretreated by protein precipitation gave recoveries which were not satisfactory for $\mathrm{MET}^{+}(151 \%)$, $\mathrm{PHEBI}^{+}(74 \%)$ and $\mathrm{PHEN}^{+}(45 \%)$. 


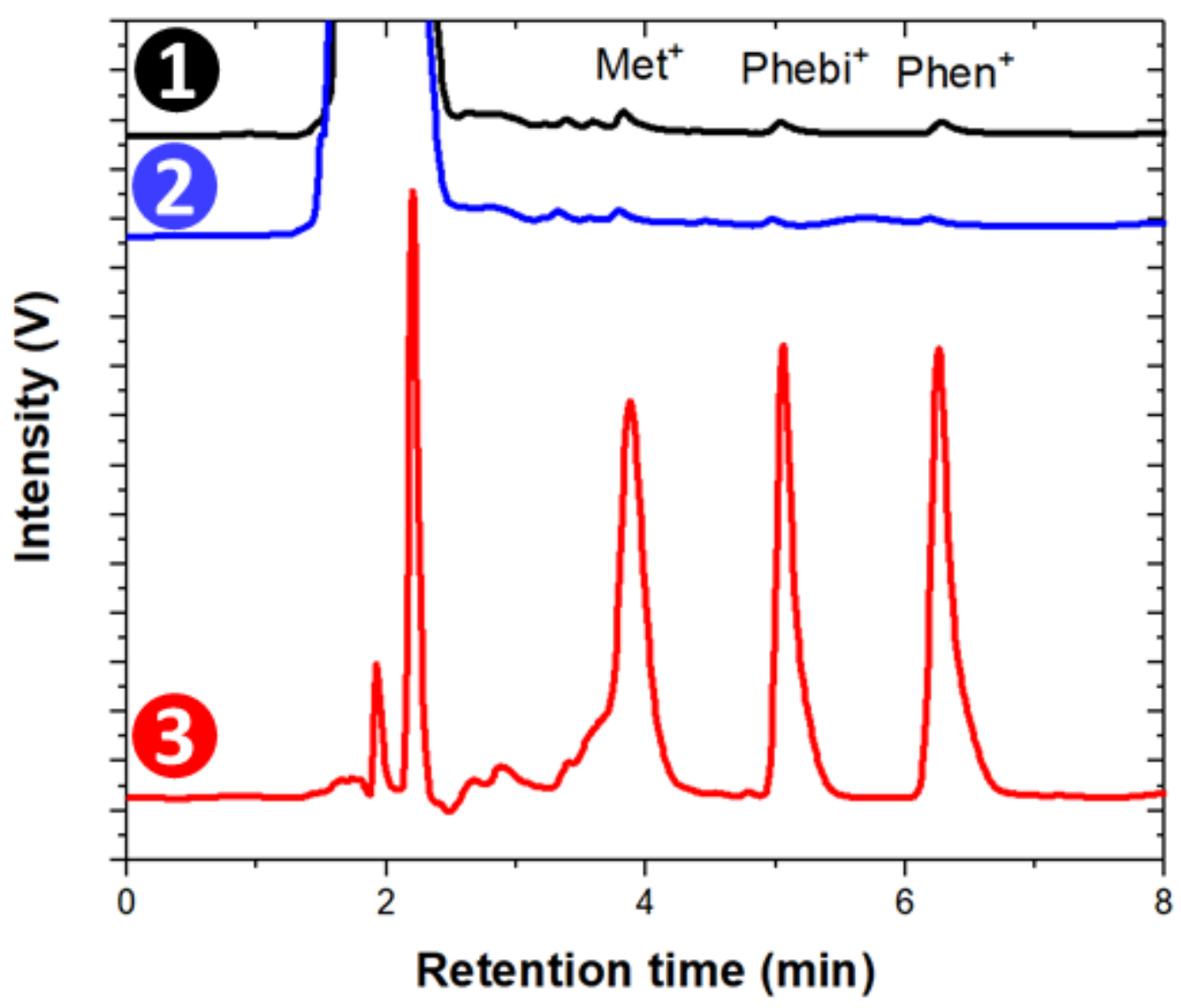

Figure 8: Chromatograms before (1) and after (2) extraction and after back-extraction (3). Extraction conditions were $\left[\mathrm{TMA}^{+}\right]_{\mathrm{o}}=10 \mathrm{mM},\left[\mathrm{TMA}^{+}\right]_{\mathrm{w}}=0.001 \mathrm{mM}, \mathrm{pH} 6, \mathrm{~V}_{\mathrm{DCE}}=2 \mathrm{~mL}, \omega=600 \mathrm{rpm}, \mathrm{t}_{\text {ext }}=15 \mathrm{~min}$. The chromatograms were obtained for sample pretreated by dilution 1:4 in de-ionized water.

Table 1: Analytical parameters for the proposed method for $\mathrm{MET}^{+}, \mathrm{PHEBI}^{+}$and $\mathrm{PHEN}^{+}$

\begin{tabular}{|c|c|c|c|c|}
\hline \multirow{2}{*}{\multicolumn{2}{|c|}{ Method development }} & \multicolumn{3}{|c|}{ Analytes } \\
\hline & & $\mathrm{MET}^{+}$ & PHEBI $^{+}$ & PHEN $^{+}$ \\
\hline \multirow{6}{*}{ With sample enrichment } & Sensitivity / $\mathrm{mV} s \mu \mathrm{M}^{-1}$ & 0.094 & 0.103 & 0.102 \\
\hline & $\mathbf{R}^{2}$ & 0.9999 & 0.9987 & 0.9988 \\
\hline & Intercept / mV s & -0.0008 & -0.0031 & 0.0002 \\
\hline & $\operatorname{LOD} / \mu \mathrm{M}$ & 0.017 & 0.068 & 0.066 \\
\hline & $\mathrm{LOQ} / \mu \mathrm{M}$ & 0.058 & 0.227 & 0.222 \\
\hline & Precision / \% & 6.84 & 6.79 & 6.89 \\
\hline \multirow{5}{*}{ Sample without enrichment } & Sensitivity / $\mathrm{mV} s \mu \mathrm{M}^{-1}$ & 0.002 & 0.002 & 0.002 \\
\hline & $\mathbf{R}^{2}$ & 0.9991 & 0.9994 & 0.9998 \\
\hline & Intercept / mV s & 0.00004 & 0.00002 & 0.00004 \\
\hline & LOD / $\mu \mathrm{M}$ & 0.903 & 0.727 & 0.438 \\
\hline & $\mathrm{LOQ} / \mu \mathrm{M}$ & 3.00 & 2.42 & 1.46 \\
\hline
\end{tabular}




\section{Conclusions}

Aqueous samples containing cationic drugs were prepared by electrochemically modulated liquidliquid extraction. This two-step method (a first extraction to an intermediate organic phase before a back extraction to an aqueous final phase) is based on the control of interfacial potential difference between two immiscible solutions by the distribution of a common ion. The principle of this approach was investigated for three cationic analytes of various hydrophilicity in clean laboratory solutions. A full extraction yield was achieved for all three drugs, including metformin. As the most hydrophilic one, it is the most difficult one to extract and commercially available methods have proven to be unsuccessful in many cases. The improved analytical performances achieved in terms of sensitivity, limits of detection and quantitation, and precision are a promise of the application of this method to a wider range of hydrophilic analytes and natural samples.

\section{Associated content}

Supporting information: Electrochemical cell for ITIES experiments; Experimental conditions for extraction and back extraction; Calibration curves for $\mathrm{MET}^{+}, \mathrm{PHEBI}^{+}$and $\mathrm{PHEN}^{+}$; Cyclic voltammograms at $\mathrm{pH} 2$ for for $\mathrm{MET}^{+}, \mathrm{PHEBI}^{+}$and $\mathrm{PHEN}^{+}$; lonic partition diagrams for $\mathrm{MET}^{+}, \mathrm{PHEBI}^{+}$and $\mathrm{PHEN}^{+}$; Experimental conditions to reach equilibrium; Principal component analysis; Determination of the interfacial potential difference at equilibrium; Control experiments with hydrophobic drug; Control experiments for non-polarized extractions; Calibration curves for $\mathrm{MET}^{+}, \mathrm{PHEB}^{+}$and $\mathrm{PHEN}^{+}$for the optimal extraction conditions; Comparison with existing methods; Additional references.

\section{Acknowledgements}

Financial support for this work by Universiti Sains Malaysia via Short Term Grant (303/PKIMIA/6313303). MNJ thanked the French Embassy in Malaysia for financial aid through Campus France programme. This research was partly funded by the Agence Nationale de la Recherche for the funding of the HYPERION project (grant number: ANR-14-CE14-0002-01). Dr Erwan André is thanked for his help on the principal component analysis.

\section{References}

(1) Collins, C. J.; Arrigan, D. W. M. Anal. Bioanal. Chem. 2009, 393 (3), 835-845. 
(2) Yamini, Y.; Seidi, S.; Rezazadeh, M. Anal. Chim. Acta 2014, 814, 1-22.

(3) Gjelstad, A.; Pedersen-Bjergaard, S. Anal. Methods 2013, 5 (18), 4549-4557.

(4) Seip, K. F.; Jensen, H.; Sønsteby, M. H.; Gjelstad, A.; Pedersen-Bjergaard, S. Electrophoresis 2013, 34 (5), 792-799.

(5) Yamini, Y.; Pourali, A.; Rezazadeh, M. Anal. Methods 2014, 6, 5554-5565.

(6) Seip, K. F.; Jensen, H.; Kieu, T. E.; Gjelstad, A.; Pedersen-Bjergaard, S. J. Chromatogr. A 2014, 1347, 1-7.

(7) Petersen, N. J.; Jensen, H.; Hansen, S. H.; Foss, S. T.; Snakenborg, D.; PedersenBjergaard, S. Microfluid. Nanofluidics 2010, 9 (4-5), 881-888.

(8) Sikanen, T.; Pedersen-Bjergaard, S.; Jensen, H.; Kostiainen, R.; Rasmussen, K. E.; Kotiaho, T. Anal. Chim. Acta 2010, 658 (2), 133-140.

(9) Petersen, N. J.; Foss, S. T.; Jensen, H.; Hansen, S. H.; Skonberg, C.; Snakenborg, D.; Kutter, J. P.; Pedersen-Bjergaard, S. Anal. Chem. 2011, 83 (1), 44-51.

(10) Petersen, N. J.; Jensen, H.; Pedersen-Bjergaard, S. Methods Mol. Biol. 2015, 1274, 171-182.

(11) Fakhari, A. R.; Sahragard, A.; Ahmar, H.; Tabani, H. J. Electroanal. Chem. 2015, 747, 12-19.

(12) Baharfar, M.; Yamini, Y.; Seidi, S.; Arain, M. B. Anal. Chem. 2018.

(13) Raterink, R. J.; Lindenburg, P. W.; Vreeken, R. J.; Hankemeier, T. Anal. Chem. 2013, 85 (16), 7762-7768.

(14) Domínguez, N. C.; Gjelstad, A.; Nadal, A. M.; Jensen, H.; Petersen, N. J.; Hansen, S. H.; Rasmussen, K. E.; Pedersen-Bjergaard, S. J. Chromatogr. A 2012, 1248, 48-54.

(15) Scanlon, M. D.; Smirnov, E.; Stockmann, T. J.; Peljo, P. Chem. Rev. 2018, 118 (7), 3722-3751.

(16) Herzog, G. Analyst 2015, 140 (12), 3888-3896.

(17) Berduque, A.; Sherburn, A.; Ghita, M.; Dryfe, R. A. W.; Arrigan, D. W. M. Anal. Chem. 2005, 77, 7310-7318.

(18) Berduque, A.; Arrigan, D. W. M. Anal. Chem. 2006, 78 (8), 2717-2725.

(19) Collins, C. J.; Berduque, A.; Arrigan, D. W. M. Anal. Chem. 2008, 80 (21), 81028108.

(20) Dryfe, R. A. W.; Kralj, B. Electrochem. commun. 1999, 1 (3-4), 128-130.

(21) Kralj, B.; Dryfe, R. A. W. J. Phys. Chem. B 2002, 106, 6732-6739.

(22) Kralj, B.; Dryfe, R. A. W. J. Electroanal. Chem. 2003, 560 (2), 127-133.

(23) Kralj, B.; Dryfe, R. A. W. Electrochem. commun. 2003, 5 (4), 325-328.

(24) Bard, A. J.; Faulkner, L. R. Eletrochemical Methods: Fundamentals and Applications, 2nd Ed.; John Wiley and Sons: New York, 2001.

(25) Samec, Z.; Trojánek, A.; Langmaier, J.; Samcová, E. J. Electroanal. Chem. 2000, 481 (1), $1-6$.

(26) Ulmeanu, S. M.; Jensen, H.; Samec, Z.; Bouchard, G.; Carrupt, P. A.; Girault, H. H. J. Electroanal. Chem. 2002, 530 (1-2), 10-15.

(27) Velický, M.; Tam, K. Y.; Dryfe, R. A. W. Anal. Chem. 2012, 84 (5), 2541-2547.

(28) Velický, M.; Tam, K. Y.; Dryfe, R. A. W. Anal. Chem. 2014, 86 (1), 435-442.

(29) Olmos, J. M.; Molina, Á.; Laborda, E.; Millán-Barrios, E.; Ortuño, J. Á. Anal. Chem. 2018, 90 (3), 2088-2094.

(30) Hung, L. Q. J. Electroanal. Chem. 1980, 115, 159-174.

(31) IWATA, T.; NAGATANI, H.; OSAKAI, T. Anal. Sci. 2017, 33 (7), 813-819.

(32) Langmaier, J.; Samec, Z.; Samcová, E.; Tůma, P. J. Electroanal. Chem. 2016, 777, 2632.

(33) Bailey, C. J.; Day, C. Pract. Diabetes Int. 2004, 21 (3), 115-117.

(34) Hussain, I.; Ali, I.; Rahman, H.; Ghani, S. S. J. Liq. Chromatogr. Relat. Technol. 2017, 
40 (12), 599-615.

(35) Wu, X.; Zhu, B.; Lu, L.; Huang, W.; Pang, D. Food Chem. 2012, 133 (2), 482-488.

(36) Martín, J.; Buchberger, W.; Santos, J. L.; Alonso, E.; Aparicio, I. J. Chromatogr. B Anal. Technol. Biomed. Life Sci. 2012, 895-896, 94-101.

(37) Nielsen, F.; Christensen, M. M. H.; Brøsen, K. Ther. Drug Monit. 2014, 36 (2), 211217.

(38) Alshishani, A.; Makahleh, A.; Yap, H. F.; Gubartallah, E. A.; Salhimi, S. M.; Saad, B. Talanta 2016, 161, 398-404.

(39) Alshishani, A.; Salhimi, S. M.; Saad, B. J. Chromatogr. B Anal. Technol. Biomed. Life Sci. 2018, 1073 (August 2017), 51-59.

(40) Lee, H. J.; Beattie, P. D.; Seddon, B. J.; Osborne, M. D.; Girault, H. H. J. Electroanal. Chem. 1997, 440, 73-82.

(41) Abraham, M. H.; Danil de Namor, A. F. J. Chem. Soc. Faraday Trans. 1 1976, 72 , 955-962.

(42) Wandlowski, T.; Mareček, V.; Samec, Z. Electrochim. Acta 1990, 35, 1173-1175.

(43) Reymond, F.; Steyaert, G.; Carrupt, P. A.; Testa, B.; Girault, H. J. Am. Chem. Soc. 1996, 118 (47), 11951-11957.

(44) Gobry, V.; Ulmeanu, S.; Reymond, F.; Bouchard, G.; Carrupt, P. A.; Testa, B.; Girault, H. H. J. Am. Chem. Soc. 2001, 123 (43), 10684-10690.

(45) Charles, B. G.; Jacobsen, N. W.; Ravenscroft, P. J. Clin. Chem. 1981, 27 (3), 434-436.

(46) Ben-Hander, G. M.; Makahleh, A.; Saad, B.; Idiris, M. J. Chromatogr. B 2013, 941, 123-130.

(47) Ben-Hander, G. M.; Makahleh, A.; Saad, B.; Saleh, M. I.; Cheng, K. W. Talanta 2015, $131,590-596$.

(48) Karami, M.; Yamini, Y.; Asl, Y. A.; Rezazadeh, M. J. Chromatogr. A 2017, 1527, 1-9.

(49) Santigosa, E.; Maspoch, S.; Ramos, M. Microchem. J. 2019, 145 (October 2018), 280286. 
Table of content Graphic

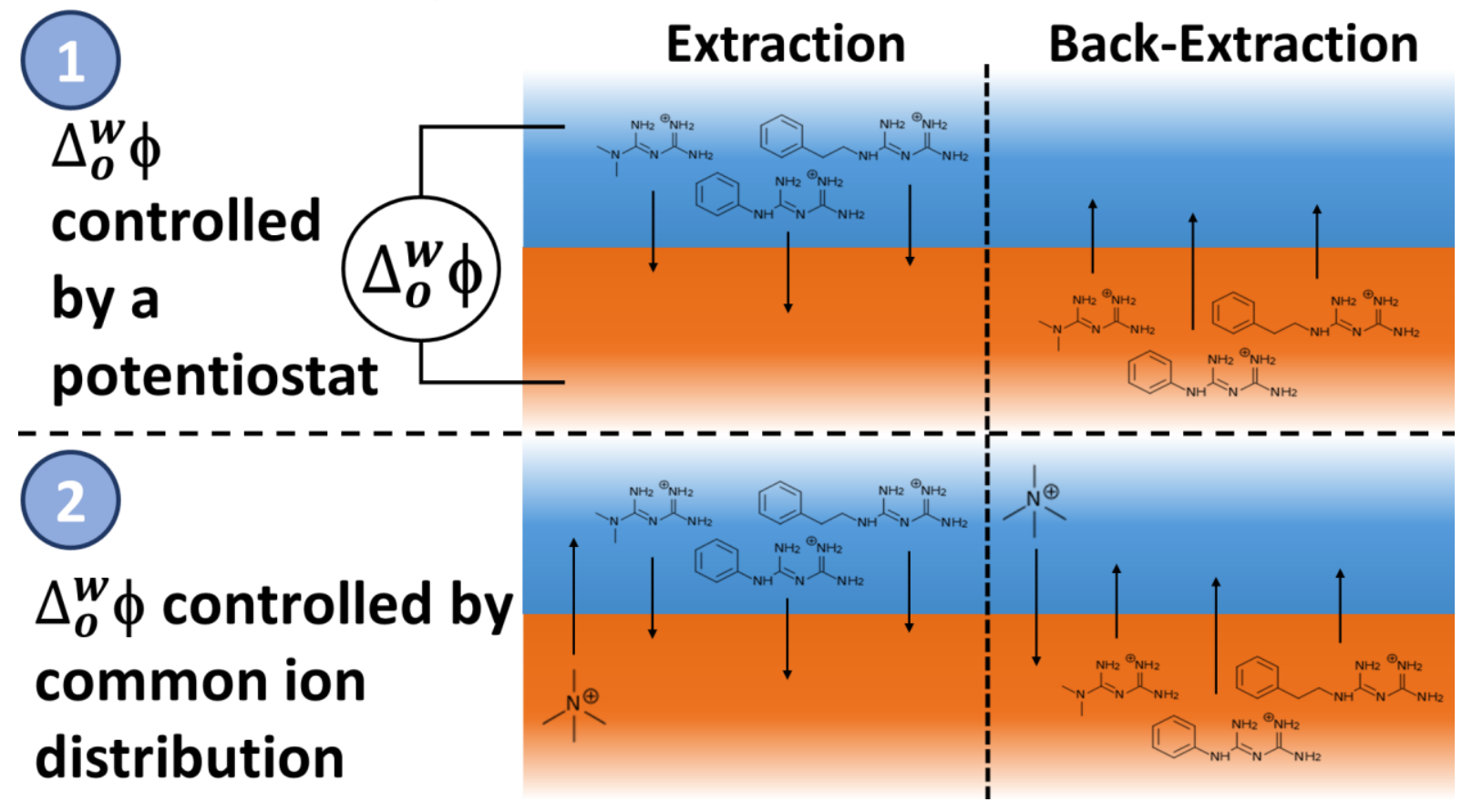

